\title{
Acceptability of a vocational advice service for patients consulting in primary care with musculoskeletal pain: a qualitative exploration of the experiences of general practitioners, vocational advisors, and patients
}

\begin{abstract}
Aims: To explore the experiences of GPs, vocational advisors and patients towards a new vocational advice (VA) service in primary care, using qualitative interviews. Methods This study was nested within the Study of Work And Pain (SWAP) cluster randomised controlled trial. The SWAP trial located a VA service within three general practices in Staffordshire. Interviews took place with 10 GPs 12 months after the introduction of the VA service, 4 vocational advisors whilst the VA service was running and 20 patients on discharge from the VA service. The data were analysed using the 'constant comparative' method, which is a variation of grounded theory. Results: The key factors determining the acceptability and perceived effectiveness of the VA service from the perspective of the three groups of stakeholders were 1) the timing of referrals to the VA, 2) the perceived lack of patient demand for the service, and 3) role uncertainty experienced by VAs. Conclusions Early vocational intervention may not be appropriate for all musculoskeletal patients with work difficulties. Indeed, many patients felt they did not require the support of a VA, either because they had self-limiting work difficulties and/or already had support mechanisms in place to return to work. Future VA interventions may be better implemented in a targeted way so that appropriate patients are identified with characteristics which can best be addressed by the VA service.
\end{abstract}

\section{Introduction}

Musculoskeletal pain has a major impact on work, with resulting work absence it is one of the largest contributors to the cost of musculoskeletal disorders [1]. In 2013/2014 the number of UK employees reporting these disorders was 526,000', leading to a total of 8.3 million lost working days [2]. There is also a growing move towards preventing unnecessary sickness absence and its deleterious effects [5, 6], with recognition that return-to-work is not a discrete, 'all or nothing' event, but rather a process in which the individual prepares for, moves closer to, and engages in work [7,8]. The issue of health and work has become a priority in both the UK and Europe [9, 10]. Within the UK there is pressure to manage the health and work interface in primary care; this is underpinned by a report by Waddell et al 
(2008) [11] stating that general practitioners (GPs) play a key role in advising and supporting patients about work, and indeed they are the primary providers of vocational rehabilitation advice. UK Physiotherapists may offer limited advice about return to work, they are not specifically trained for this purpose, and the responsibility largely falls with the GP. However, both Waddell et al (2008) [11] and the National Institute for Health and Care Excellence pathway for managing long-term sickness absence (2009) [12] emphasise the need to involve other appropriate health professionals who have specific skills and expertise in vocational rehabilitation, that can deliver vocational advice and support to patients. GPs have reported that they lack the training and are ill-equipped to deal with patients' concerns about work (31).

Vocational rehabilitation is directed to, and has the primary goal of, improving capability for work and translating that into actually working. Vocational rehabilitation has been defined as "a process to overcome the barriers an individual faces when accessing, remaining or returning to work following injury, illness or impairment" [16]. As such, vocational rehabilitation may be considered a complex intervention. Complex interventions in healthcare inevitably involve human interactions and consequently include a 'social' dimension which needs to be evaluated to understand barriers and enablers of the intervention (Craig et al 2008) [17]. In this paper we examine the acceptability of the introduction of a vocational advice service into primary care through the Study of Work and Pain (SWAP) cluster randomised controlled trial (RCT) [18]) from the experiences of three stakeholders.

\section{Methods}

This qualitative study was part of a cluster RCT and involved three groups of participants; General practitioners (GPs) at participating general practices, vocational advisors (VAs) offering the new service and patients referred to the VA [18]. Ethical approval was obtained from XXX in April 2012 (reference: XXX) [Blinded].

\section{VA service}

The VA service was located in three GP intervention practices in Staffordshire for 18 months. GPs were asked to refer patients who were employed but who consulted with musculoskeletal 
pain and were absent from work for less than six months or were struggling at work due to pain. The VA service was based on stepped care and case management principles.

Training and mentoring of vocational advisors

Four healthcare practitioners were recruited to vocational advisor posts to deliver the new VA service, (three actually delivered the service). VAs attended a four day training programme (developed by the team and reported separately), and a half day update prior to the start of the service. Monthly mentoring meetings took place where the VAs provided each other with peer support and discussed issues arising with clinicians experienced in managing workrelated issues. All three treating VAs were trained physiotherapists. Further information about the intervention development is published elsewhere [18].

Qualitative interviews

Semi-structured interviews were used to explore the experiences of the VA service from the perspectives of GPs, VAs and patients. GP qualitative interviews $(n=10)$ at 12 months after commencement of the service, were conducted in the GP consulting room and lasted 15 to 45 minutes, interviews were audio-recorded and transcribed. All GPs in each practice were approached for interview. The majority of GPs who were approached via a study coordinator and a practice manager, agreed to an interview. Reasons for non-participation included: a) not in the practice at the time of visit by research team for interview, b) too busy. Topic guides focused discussions on barriers and enablers of the VA service, the influence of practice routines, procedures, and practice culture. VA's were interviewed four times, at baseline (prior to the start of the VA service but after the VA training programme) and at 1, 6 and 12 months after the VA service began Interviews explored how their knowledge, confidence and experience of providing the VA service evolved. VA's were contacted informally via email by the study PI to arrange a convenient time for an interview. Interviews were conducted in person at the research team's University department. Patients $(n=20)$ consenting to be contacted were invited to take part in semi-structured telephone interviews following discharge from the VA service. We sampled our participants from the 'intervention' arm of the trial (those receiving vocational advice - 158 patients) using the characteristics of gender, age and musculoskeletal complaint to recruit a broad range of patients and opinions. Patients were approached by letter, following which an interview time and date was agreed. The final sample was broadly representative of the population of patients in the intervention arm of the 
trial, in relation to age, sex and musculoskeletal problems. We mailed invitation letters to patients in the intervention arm, in three separate phases, resulting in a total of 102 letters to consenting trial participants, recruting a total of 20 participants (11 women and 9 men). We do not have data on reasons for refusal to participate, and we did not follow up refusals with subsequent invitations. Table 1 describes the patients' characteristics. The focus of the interviews was on how beneficial the VA contact had been and whether patients perceived added value in the VA advice. Interviews also explored the patients' specific musculoskeletal problem and the impact on their work (and vice-versa). Following 20 interviews no new insights from the data were being identified, culminating in a decision to end data collection. Interviews lasted approximately 40 minutes on average, and were audio-recorded and transcribed verbatim.

\section{Analysis}

Transcripts were analysed and coded independently by two research team members, who met regularly to compare and discuss their interpretations throughout the duration of the fieldwork, using a variation of grounded theory, particularly the 'constant comparative' method. Both researchers also conducted the interviews. [19]. The themes were analysed in parallel with data collection rather than left to the end, as consistent with qualitative research methodology. Each participant groups' interviews were coded resulting in the generation of three separate coding frameworks (eg. for the GPs, VAs and patients) which were then discussed by the wider research team at three half day meetings, to refine the key themes. The codes were eventually adapted and amalgamated into three separate coding frames, to provide a final framework and overview of the themes as a whole. Results will be presented using direct quotations to illustrate the key themes relating to stakeholder experiences and perceived acceptability of the VA service.

\section{Results \\ GPs'views}

GPs suggested that although VAs could provide an alternative way of managing patients with complex work-related difficulties there was a lack of engagement and feedback between them and VAs leading to a mismatch between the objectives of the VA service, to support a faster return-to-work, and GPs' clinical management. The strict referral criteria were an obstacle to GP acceptability. These key barriers are discussed with examples below. 
Feedback

A key source of confusion for GPs (eg. the potential value of the VA versus uncertainty as to their role) was the lack of feedback about the impact of the VA service on individual patients.

......if you're only referring one (patient) every three or four weeks, you're not that confident about what the service can do and how it should be done, you're not getting that, kind of, feedback. When you start referring a few more you see that there is positive benefits to it. (GP 5)

The analysis highlights two issues: first, GPs were unsure about how to apply the referral criteria leading to a low initial number of patients referred. Second, as GPs claimed they did not receive feedback from the VAs on whether patients' work problems had been resolved they were unclear about the effectiveness of the service.

\section{"Authority"}

The majority of GPs viewed the VA as offering a 'signposting' facility, but also someone with limited authority to enforce changes to employment arrangements of patients.

If you signpost to your employer, saying that you can go and talk to your employer about this, if the employer is not engaged then it still doesn't help. (GP 20)

GPs were sceptical about the effectiveness of the VA where the employer refused to accommodate the patient's musculoskeletal pain problem or work difficulties. Scepticism related to GPs feeling that VAs' suggestions cannot be followed up by patients because of reasons beyond their control. This presented a notable barrier to service acceptance by GPs.

And that's all I hear, 'Do you want me to do you a sick note for lighter duties? Do you want me to do this?' 'I can't, if you do that I'll lose $20 \%$ of my pay. I can't afford to go on part time. I can't afford to. I just need more pain killers because I have to stay at work.' (GP 6) 
According to this GP, patients often requested help with their pain problem that was interfering with work performance rather than with their specific work difficulties.

\section{Timing}

A central theme identified by GPs, but also acknowledged by VAs and patients was around the appropriate timing of referral to the VA service. The quotation below refers specifically to the 'timing' of the service which was aimed towards patients very early in their episode of work absence or those struggling to remain in work.

So the problem is, that I don't refer the month one, because half the time I'm not convinced it's gonna become a significant issue. And the people I want to refer are people who, maybe, have had arthritis in their knee or back pain for the past four or five years. (GP 6)

Timing was a key factor in GPs' assessment of the suitability of patients for the service, which we identified as the length of time an individual had been off work.

\section{Flexibility of referral criteria}

Our argument in this paper builds on the sense-making process of GPs, who expressed thoughts about what they believed the VA service ought to be for, but which was often at odds with what was formally defined as their role in the trial (to refer only patients with musculoskeletal pain). GPs felt that VAs should deal with patients with a broader range of long-term conditions. GPs also claimed that they relied on their own experience of forecasting what will become a chronic problem, which again did not accord with the referral criteria; hence the disjuncture between their routine clinical approach of 'wait and see' and the proactive management required by the service to refer patients to the VA.

I guess, from my perspective, I know which sorts of patients I want...It's that thing that, actually, exclusion criteria suddenly create these barriers where you're not allowing us to make a judgement .... (GP 6)

GPs stated that patient complexity was a priority issue in their everyday practice, but they perceived that these were not dealt with by the VA service whose focus was only on 
musculoskeletal problems. Therefore, the referral criteria did not always fit into their everyday practice. This creates a level of ambiguity and leads to the adoption of two strategies by GPs: first, not referring patients who could be eligible; second, referring people who do not fit referral criteria.

\section{VAs' views}

VAs claimed that early referral of patients with little or even no work absence meant that their vocational skills could not be adequately deployed, due to the relatively limited work difficulties. They believed that for most patients referred to them, resolution of the health problem would lead to an improvement of work difficulties, and since many patients were able to self-manage their pain and return-to-work the VAs were unable to offer additional help.

But we also have to demonstrate that we're adding value to their patients which is difficult to do when the patient is being referred so early down the line... So the difficulty is weeding out those who really need the advice and adding value really to the service itself because essentially if we're just contacting patients who have already put together a (return-to-work) plan we're not going to be adding value. (QVA3 6 months)

The following VA is alluding to the danger that the VA service may be perceived as a useful referral pathway for 'challenging' patients.

They might not refer appropriate people, they might send people who are just difficult for them to manage and they'll think there's somewhere to send them... (QVA4 6 months)

It is important to note that patients presenting with either long or short term work and pain difficulties to their GP could both be viewed as 'challenging'.

The problem of 'inappropriate' referrals to the service could potentially be resolved in two ways: improving clarity of referral criteria, or routinizing the service as part of the repertoire of options for GPs to support patients. For instance, the process of familiarisation and 
increased awareness of the VA service by GPs is likely to lead to 'fine tuning' of the referral criteria, so only those patients who are judged suitable are referred.

\section{Social etiquette}

There was a need for 'soft' conversations between VAs and GPs to foster greater engagement and awareness of the VA's role.

Once I've hooked a GP, I've tried to then feed him [laughs] with information, so that, hopefully, he'll generate more referrals. But that's a bit frustrating if then they've sent one and it's ineligible, because they then think, 'Oh, it's not suitable,' and, you know, 'who is suitable then?' So, then, having a softer conversation with someone about, 'Well, actually, that was great. Thank you for the referral, but I couldn't help him this time, blur, blur.' (QVA2 12 Months)

In situations where VAs spotted a chance to talk with GPs, they exercised professional etiquette as means of facilitating GP engagement with the VA role, though on the whole this strategy had limited effect as opportunities for conversation were rare given the busy working environment of general practice.

\section{'Selling it the right way'}

VAs expressed some frustration over their lack of awareness about, and ability to control, the way patients were identified as suitable for referral to a VA and how the VA service was initially presented to patients by GPs.

I think the GP's time constraints limits them in identifying or delving deeper into what, you know what the real issues are. So a five minute consultation there's only so much a GP can get and extract during that period of time with the patient and it takes a very skilful GP to be able to extract all that information within that very small space of time. (QVA3 6 months)

VAs thought that the way GPs explained the VA service to patients did not relate to patients' own normative assumptions regarding work participation, absence and managing their work 
and pain problem. This suggests that 'one size does not fit all', and GPs need to align their explanations with the expectations of patients.

\section{Role tensions}

VAs reported role tensions between their existing professional training (physiotherapy) which they were discouraged to deploy during VA consultations, and their new VA role. They reported feeling that they 'shifted' into their more traditional role as a physiotherapist when they felt unable to help patients with work difficulties. Again, this seems directly related to the type of patients referred to the VA service with short-term work difficulties.

But I think you do go back to your comfort zone. I just know physio and I know I'm happy with that and I can see the benefit of it. This is such a new role that that's difficult to see sometimes (QVA3 6 months)

VAs used their physiotherapy knowledge and training to enhance their relationship with patients in circumstances when they could not resolve their work problems.

\section{Patients' views}

Many patients suggested that the VA service offered limited benefits. One reason was that they believed they were referred inappropriately since they did not require support to returnto-work, echoing the sentiments of both VAs and GPs.

Yeah it was very nice of her to offer the advice but, you know, we'd already been through all the alternatives. The real alternative was that you give your job in and pack everything up. (Patient 31-Male-64 years)

Many patients did not believe that the VA could help them beyond what they were already doing for themselves. This was particularly the case with self-employed people.

I got the impression that all she tried to do was just trying to get me back into work. And I thought, 'Well, I'm doing that myself. I don't want to be off work. I've had no wages. Honestly. (Patient 79-Male-55 years) 
A VA's input was more useful in instances where patients experienced long-standing work difficulties or who had long term chronic health problems.

VA role uncertainty

Patients were confused about the boundary between GPs and VAs in managing work related problems, raising the question of who had the appropriate skills and knowledge to offer effective help.

I think, initially, I thought, you know, 'How far do I take things with her?' you know, 'Who do I go to, the GP or the vocational advisor?' I think that some clarification was needed with that [right], as to who was actually in charge. (Patient 34-Female 39 years)

Yet others were sceptical about a VAs true intentions who they thought might attempt to conduct a fit for work assessment on their eligibility to work.

You hear of these things like Fitness to Work, Fitness to Practice and whatever, which [yeah], you know, you're thinking, 'Is my job gonna be safe?' and that. (Patient 128Female-53 years)

These examples indicate the importance of role clarity so that patients have accurate information about the service provided. Other patients echoed GPs' sentiments that VAs lacked the authority to enforce change in the workplace.

It's just that I feel that they would have been pretty powerless to do anything had my situation been more severe [right] with my current employer [right]. (Patient 10-Male51 years)

Other patients expressed the opinion that a VA service was inappropriate for them as they preferred to either resolve the work and health difficulty alone or to visit the GP.

So if I come to that I was in pain I'd go to my doctor rather than phone in [to a VA]. (Patient 458-Female-50 years) 
This suggests that the primary problem for many patients referred to the VA may be the underlying musculoskeletal condition, not 'work', echoing the VAs' sentiments. This could also reflect uncertainty about the role of the VA on the patients' part.

\section{'Soft' side}

When patients received advice from the VA, they valued the moral support and appreciated the less 'tangible' benefits such as having 'someone to talk to'. Advice on returning to work or how best to manage the work difficulty was felt to be less useful.

So it was good to have the phone call support, which was more independent, because that was over the telephone and I felt that he was looking after my best interests rather than work's. The occupational health lady was looking after work rather than.... (Patient 338-Female-47 years)

Others believed that the VA could add legitimacy to their pain problem.

You felt that you'd got somebody else on your side, and [yeah] supporting you, really, because, you know, if you've got a broken arm they can see it, it's in a cast and whatever, whereas, you know, they do say a lot of people 'put on' the fact that they’ve got back pain, depression, or whatever. (Patient 636-Male-54 years)

\section{Discussion}

The findings identify three overarching themes espoused by the three groups of stakeholders; a) timing of referrals b) patient need and c) VA role uncertainty.

The timing of referrals appeared to be central to the acceptability of the VA service by all three stakeholders. Whilst early intervention has been advocated to prevent long-term sickness absence it appears that intervening too early is also problematic, as many patients in our study self-managed their pain and work absence and felt that they did not need a service to assist with this [4]. There are no other studies that have attempted a work-focused intervention at such an early stage of work absence. However, early intervention has been found to be effective when 'early' is defined as after two weeks of absence [20, 21]. Our 
results suggest that waiting until work absence becomes a little more established, when patients are struggling to manage it themselves, is perhaps the time to intervene. A period of 'watchful' waiting and ongoing assessment before referring to the VA service might alleviate some of the problems highlighted here. It would allow GPs to ensure that they are identifying those patients who might benefit the most from the VA and it would increase the likelihood that it could offer added value if targeted at the group of patients with more complex work difficulties.

The second key theme related to patient need for the VA service. Patients claimed that VA input was largely unnecessary because they had either returned-to-work or were already in receipt of help and support. The emphasis on return-to-work was felt to be too strong and required further refinement, so that VA advice could be tailored to the specific needs of individual patients, such as their difficulties with their pain problem. Patients were uncertain about the precise purpose of the VA role and were consequently reluctant to seek advice [22]. The findings can be summarised in theoretical terms as a system of matching and mismatching expectations, representing different stakeholder groups. Based on May et al's (2010) Normalization Process Theory the service lacked 'coherence' to all stakeholders involved, namely the 'fit' with their expectations of how work difficulties should be approached [23].

The third key theme revealed the presence of VA role uncertainty, expressed in different ways by all stakeholders. Professionals providing vocational rehabilitation are typically trained in a health-related occupation. Clinical expertise might therefore be considered an important prerequisite for the role [24]. The VAs who delivered the service were physiotherapists who sometimes applied their physiotherapy knowledge to provide advice when work difficulties seemed too challenging, as a means of maintaining continuity within the professional-client encounter. This was a resourceful attempt to shift focus back to the clinical problem as a means of 'maintaining' the relationship with the patient following unsuccessful attempts to resolve work difficulties. A finding also reported by Blakeman et al (2011) in relation to the adoption of alternative strategies by GPs as a mechanism for preserving the doctor-patient relationship [25]. As such, work and health problems were viewed separately by the VAs requiring different approaches for resolution; health required 
clinical knowledge whilst work difficulties demanded an altogether different skill set which the VAs were beginning to acquire.

There are competencies that have been highlighted and should be accounted for when recruiting to the role of vocational advisor. These include clinical knowledge which was not found to be a key requirement in either a systematic review or focus groups with vocational advisors $[26,27]$. It has been suggested that interpersonal skills may be more important than a health background when defining the VA role $[29,30]$. The level of clinical knowledge required for the VA role is centred on understanding the potential for disability or functional limitations that a condition leads to, and hence the likely impact on work participation [24]. Coutou et al (2011) stress the importance of acknowledging workers' health, illness and work related representations, and that rehabilitation success is determined by workers transitioning from a less mechanistic to a more functional (eg. what they are able to achieve within their limits) view of health [28]. This represents a shift from a solely biomedical to a social model of rehabilitation. The purpose of our study was to support the management of patients' work difficulties over and above the clinical problem. However, the integration of the VAs clinical background within the newly acquired VA role may have given them greater credibility visa-vis GPs and patients, and the option to apply their clinical skills to the overall vocational rehabilitation programme. Indeed, they claimed that their clinical skills could add value to their new vocational advice role, since they could offer advice on phsyical pain problems if they felt unable to move forward with work difficulties. Finally, it is important to recognise that changing VAs' and GPs' behaviour to facilitate engagement in a new intervention is not only about removing organisational obstacles but also equipping professionals with the skills to negotiate occupational boundaries in complex multidisciplinary contexts.

\section{Strengths and limitations}

We employed a qualitative grounded theory study design for this complex intervention, in preference to using a predetermined theoretical framework, which has led to hitherto unreported insights. These will provide a helpful resource for future similar vocational advice interventions in primary care in the UK and internationally. The inclusion of three stakeholders was a strength of this study. GPs and the VAs were interviewed at multiple time-points which allowed the examination of acceptability over time. We did not interview employers given that there was no direct contact between the VAs and employers in the trial. 
The introduction of new services into established routines will involve behaviour change, and an understanding of how these changes impact on those affected ensures that embedding new occupational roles in healthcare settings can take account of "lessons learned".

\section{Funding}

This paper presents independent research funded by the National Institute for Health Research (NIHR), under its Programme Grants for Applied Research funding scheme: "Optimal management of spinal pain and sciatica in primary care" (NIHR-RP-PG-070710131). NF and AB are funded by an NIHR Research Professorship for NF (NIHR-RP-011015. GW-J is funded by an NIHR Research Post-doctoral Fellowship (PDF-2009-02-54). The views expressed are those of the authors and not necessarily those of the NHS, the NIHR or the Department of Health. This research was funded by the NIHR Collaboration for Leadership in Applied Health Research and Care Yorkshire and Humber (NIHR CLAHRC YH). www.clahrc-yh.nihr.ac.uk. The views and opinions expressed are those of the author(s), and not necessarily those of the NHS, the NIHR or the Department of Health.

\section{References}

1. Lewis M, Wynne-Jones G, Barton P, Whitehurst DGT, Wathall S, Foster NE, Hay E, Van der windt DAWm, (2015) Should General Practitioners issue a sick certificate to employees who consult for low back pain in primary care? An assessment of clinical outcomes and cost utility, Journal of Occupational Rehabilitation, Sep;25(3):577-88. doi: 10.1007/s10926-014-9564-z.

2. Health and Safety Executive, Musculoskeletal Disorders in Great Britain 2014, http://www.hse.gov.uk/statistics/

3. van Rijn R, Roebroek S.J.W, Brouwer S, Burdorf A (2014), Influence of poor health on exity from paid employment: A systematic review, Occupational and Environmental Medicine Vol 71 pg 295-301

4. Waddell G, Burton AK, Kendall NAS. Vocational rehabilitation - what works, for whom, and when? (Report for the Vocational Rehabilitation Task Group). TSO. London. ISBN 9780117038615. (2008).

5. American College of Occupational and Environmental Medicine Published in September 2006 JOEM 
6. Varekamp I, Verbeek J.H.A.M, van Dijk F.J.H, (2006), How can we help employees with chronic diseases to stay at work? A review of interventions aimed at job retention and based on an empowerment perspective, Int Arch Occup Environ Health Vol 80 pg 87-97

7. Wasiak R, Young AE, Roessler RT, McPherson KM, van Poppel MNM, Anema JR. 2007. Measuring return to work. J Occup Rehabil 17: 766-781.

8. Young AE, Roessler RT, Wasiak R, McPherson KM, van Poppel MNM, Anema JR. 2005a. A developmental conceptualization of return to work. Journal of Occupational Rehabilitation 15: 557-568.

9. Black C. Review of the health of Britain's working age population: Working for a healthier tomorrow. London: TSO (2008).

10. Fit For Work Europe. http://www.fitforworkeurope.eu

11. Waddell G, Burton AK, Kendall NAS. Vocational rehabilitation - what works, for whom, and when? (Report for the Vocational Rehabilitation Task Group). TSO. London. ISBN 9780117038615. (2008).

12. National Institute for Health and Care Excellence, Managing long-term sickness and incapacity for work. NICE Public Health Guidance 19. (2009).

13. Department for Work and Pensions, Evaluation of the Fit for Work Service pilots: first year report, (2012) Department for Work and Pensions Research Report No 792

14. Department for Work and Pensions, Evaluation of the 2010-2013 Fit for Work Service pilots: final report, (2015) Department for Work and Pensions Research Report No 896

15. Waddell G, Burton A.K, Occupational health guidelines for the management of low back pain at work: evidence review, (2001), Occupational Medicine Vol 51(2) pg $124-135$

16. Department for Work and Pensions (2004). Developing a framework for vocational rehabilitation: Qualitative Research. Available at http://webarchive.nationalarchives.gov.uk/20130128102031/http://statistics.dwp.gov. uk/asd/asd5/report_abstracts/rr_abstracts/rra_224.asp

17. Craig P, Dieppe P, Macintyre S, Michie S, Nazareth I, Petticrew M, Developing and evaluating complex interventions: the new Medical Research Council guidance. BMJ2008;337:a1655 
18. Bishop, A., Wynne-Jones, G., Lawton, S.A., van der Windt, D., Main, C., Sowden, G., Burton, A.K.,Lewis, M., Jowett, S., Sanders, T., Hay, E.M., Foster, N.E. And SWAP study team, (2014) Rationale, design and methods of the Study of Work and Pain (SWAP): a cluster randomised controlled trial testing the addition of a vocational advice service to best current primary care for patients with musculoskeletal pain (ISRCTN 52269669). BMC Musculoskelet Disorders, 15 (232).

19. Strauss S and Corbin J (1990) Basics of Qualitative Research: Grounded Theory, Procedures and Techniques. Newbury Park: Sage.

20. van der Klink J.J.L, Blonk R.W.B, Schene A.H, van Dijk, F.J.H, Reducing long term sickness absence by an activating intervention in adjustment disorders: a cluster randomised controlled trial, (2003), Occupational and Environmental Medicine Vol 60 pg 429-437

21. Carroll C., Rick J., Pilgrim H., Cameron J., Hillage J. (2010), 'Workplace involvement improves return to work rates among employees with back pain on longterm sick leave: a systematic review of the effectiveness and cost-effectiveness of interventions', Disability and rehabilitation, 32(8), pp. 607-21.

22. Pullon S, McKinley E, Stubbe M, Todd L, Badenhorst C, Patients and health professionals perceptions of teamwork in primary care. (2011) Journal of Primary Health Care, Vol 3(2) pg 128-135

23. May C, Finch T: (2009). Implementing, embedding, and integrating practices: an outline of Normalization Process Theory. Sociology 2009, 43 (3): 535-554.

24. Pransky G, Shaw W.S, Loisel P, Hong Q.N, Desorcy B, Development and validation of competencies for return to work coordinators, (2010) Journal of Occupational Rehabilitation Vol 20(1) pg 41-48

25. Blakeman T, Chew-Graham C, Reeves D, Rogers A, Bower P. The Quality and Outcomes Framework and self-management dialogue in primary care consultations: a qualitative study. Br J Gen Pract. 2011 Oct; 61(591)

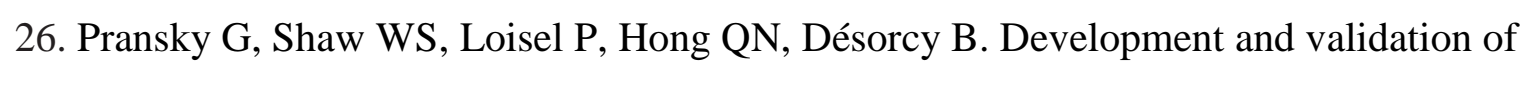
competencies for return to work coordinators. J Occup Rehabil. 2010 Mar;20(1):418.

\begin{tabular}{l|l|l||l|l|l|}
\hline 27. & Gardner BT, & Pransky G, & Shaw WS, & Hong QN, & Loisel P. Researcher perspectives on \\
\hline
\end{tabular} competencies of return-to-work coordinators. Disabil Rehabil. 2010 ;32(1):72-8. 
\begin{tabular}{l|l|l|l|l|l|l|l|}
\hline 28. & Coutu MF, & Baril R, Durand MJ & Côté D, & Cadieux G Health and illness representations \\
\hline
\end{tabular} of workers with a musculoskeletal disorder-related work disability during work rehabilitation: a qualitative study.J Occup Rehabil. 2011 Dec;21(4):591-600.

29. Morrison J: Work, fit notes and occupational health. Br J Gen Pract 2010, 60(579):715-716.

30. Rannard A, Gabbay M, Sen D, Riley R and Britt D. Feasibility trial of GP and casemanaged support for workplace sickness absence Primary Health Care Research \& Development 2014; 15: 252-261.

31. Mowlam, A. \& Lewis, J. (2005) Exploring how General Practitioners work with people on sick leave, London: Department for Work and Pensions. 